\title{
AQUEOUS STABILITY STUDIES OF POLYETHYLENE GLYCOL AND OLEIC ACID-BASED ANIONIC SURFACTANTS FOR APPLICATION IN ENHANCED OIL RECOVERY THROUGH DYNAMIC LIGHT SCATTERING
}

\author{
Yan Irawan $^{1 *}$, Ika Juliana ${ }^{1}$, Indri Badria Adilina ${ }^{1}$, Yani Faozani Alli ${ }^{2}$ \\ ${ }^{1}$ Research Center for Chemistry-LIPI, Kawasan PUSPIPTEK Serpong, South Tangerang 15314, \\ Indonesia \\ ${ }^{2}$ Research and Development Center for Oil and Gas Technology-LEMIGAS, Jl. Ciledug Raya Kav. 109 \\ Cipulir-Kebayoran Lama, South Jakarta 12230, Indonesia
}

(Received: February 2017 / Revised: May 2017 / Accepted: October 2017)

\begin{abstract}
The present study investigates the aqueous stability of polyethylene glycol and oleic acid- based anionic surfactants through the dynamic light scattering (DLS) and zeta potential methods, for application in enhanced oil recovery (EOR). Polyethylene glycol dioleate sulfonate (PDOS) surfactant solutions were prepared in concentrations of $0.05,0.1,0.3,0.5$, and $1 \mathrm{wt} \%$ in deionized water. Aqueous stability of PDOS was assessed by measuring the droplet size over five days, using nano particle analyzer HORIBA SZ-100 at $25^{\circ} \mathrm{C}$. Results show that good aqueous stability of PDOS was achieved at concentrations of 0.1 to $1 \mathrm{wt} \%$, but with the droplet size becoming unstable at the lowest concentration of $0.05 \mathrm{wt} \%$. The polydispersity indices were classified into polydisperse distribution type recorded as 0.3 to 0.5 at concentrations of 0.05 and $0.1 \mathrm{wt} \%$ and 0.2 at concentrations of 0.3 to $1 \mathrm{wt} \%$. The critical micelle concentration (CMC) of PDOS was $0.3 \%$ and the interfacial tension of PDOS surfactant above the CMC was around $10^{-3} \mathrm{dyn} / \mathrm{cm}$. The zeta potential of PDOS surfactant without the addition of salt in concentrations of $0.05,0.1,0.3,0.5$, and $1 \mathrm{wt} \%$ was highly stable up to -96.8, -90.5, -89.6, 82.3, and $-64.4 \mathrm{mV}$, respectively. With the addition of salt they were moderately stable at a concentration of $1 \mathrm{wt} \%$. The conductivity increased with increasing concentration. The zeta potential of PDOS with the addition of salt was moderately stable in a concentration of $1 \%$. Although PDOS with concentration of $0.05 \%$ showed a high value of zeta potential with the addition of salt, there is no guarantee that the PDOS surfactant solution will be stable for five days.
\end{abstract}

Keywords: Aqueous stability; Dynamic light scattering; Oleic acid; Polyethylene glycol

\section{INTRODUCTION}

In a mature oil field over half of the original reserve of oil is retained in the reservoir after primary and secondary recovery. Such reserves may be recovered by tertiary recovery schemes through enhanced oil recovery (EOR) techniques, such as chemical flooding. As one of the injected chemicals in chemical flooding, surfactants have a role to play in releasing the trapped oil by lowering the interfacial tension between oil and water. Aqueous stability of surfactants, or the concentration at which surfactants will work as micelles in chemical flooding, are important factors in guaranteeing the homogenizing properties of the chemicals injected into the reservoir and thus in optimizing oil production. It is therefore interesting and important to

*Corresponding author's email: yanirawan.p2k@gmail.com, Tel: +62-21-5422-0808, Fax: +62-21-5422-0800

Permalink/DOI: https://doi.org/10.14716/ijtech.v8i8.690 
correctly and accurately identify this factor (Mandavi, 2008).

Surfactant micelles have been studied using various techniques, including dynamic light scattering (DLS) (Birdi, 1997; Dominguez, 1997; Nakahara, 2005). DLS is a technique used for particle sizing of samples, typically in the sub-micron range. The technique measures timedependent fluctuations in the intensity of scattered light from a suspension of particles undergoing random, Brownian motion. Analysis of these intensity fluctuations allows for the determination of the diffusion coefficients, which in turn yield the particle size through the Stokes-Einstein equation (Malvern, 2011).

Nagi et al. (2014) used DLS to study the characteristics of micelles formed by surfactants and polymer mixtures for EOR. The size and distribution of micelles formed in aqueous solution by different surfactant mixtures and flow modifier type Hydrolized Polyacrilamide (HPAM) polymer could be explained by DLS data to confirm their hypothesis. Meanwhile, Babu et al. (2015) used DLS to characterize polymeric surfactants such as polymeric methyl ester sulfonate (PMES) for chemical EOR. Their results show that hydrodynamic diameter (in nanometers) increases with increasing PMES surfactant concentration. Conversely, hydrodynamic particle diameter decreased with the addition of salt due to disaggregation of molecules (Nilanjan, 2016).

The authors of this paper have previously reported a synthesis and characterization of palm oil and polyethylene glycol-based anionic polymeric surfactants (Irawan, 2015; Irawan, 2017). According to these previous reports, synthesis produced nonionic and cationic surfactants of polyethylene glycol monooleate (PMO), polyethylene glycol dioleate (PDO), polyethylene glycol monooleate sulfonate (PMOS), and polyethylene glycol dioleate sulfonate (PDOS). Fourier-transform infrared spectroscopy (FTIR) analysis showed that the products produced new peaks as follows: $1722.43 \mathrm{~cm}^{-1}$ (PMO); $1728.22 \mathrm{~cm}^{-1}$ (PDO) indicating a C-O bond; $1249.87 \mathrm{~cm}^{-1}$ (PMO); $1242.16 \mathrm{~cm}^{-1}$ (PDO) indicating a $\mathrm{C}-\mathrm{O}-\mathrm{C}$ bond as a result of an esterification reaction. Peaks at $1180.44 \mathrm{~cm}^{-1}$ (PMOS) and $1228.66 \mathrm{~cm}^{-1}$ (PDOS) indicated S-O bonds resulting from a sulfonation reaction. Analysis of acid value, ester value, and saponification value was conducted to confirm the synthesis of PMO, PDO, PMOS, and PDOS. Soluble polymeric surfactants in water at room temperature were seen in concentrations of $0.1 \%$ and $0.3 \% \mathrm{wt} \%$; meanwhile, the surfactant solution became less dispersed and milky at a higher concentration of $0.5 \%$. The smallest particle size was observed for both the sulfonated products PMOS and PDOS (Irawan, 2017).

The aim of this study is to further investigate the preparation of PDOS surfactant for EOR application measured by DLS in various surfactant concentrations. The zeta potential of PDOS is measured to understand the relation between particles or colloidal dispersion systems and to sample dispersion stability. The data is also supported by interfacial tension analysis.

\section{EXPERIMENTAL METHODS}

\subsection{Material}

PDOS (Irawan, 2017), deionized water, synthetic water, crude oil of X field and sodium chloride.

\subsection{Aqueous Stability Analysis}

The aqueous stability of PDOS was assessed by measuring droplet size as a function of time using HORIBA Nano Particle Analyzer SZ-100 at $25^{\circ} \mathrm{C}$. The laser wavelength was $532 \mathrm{~nm}$ (DPSS laser) with a scattering angle of $90^{\circ} \mathrm{C} / 173^{\circ} \mathrm{C}$. The refractive index of water as a dispersion medium was 1.333. The principles of measurement used were the photo correlation method and DLS, with a measurement size range of $0.3 \mathrm{~nm}$ to $8 \mu \mathrm{m}$. PDOS solutions were prepared in wt $\%$ concentrations of $0.05,0.1,0.3,0.5$, and 1 in deionized water. The samples 
were kept sealed at room temperature. All particle size measurements were performed in duplicate and the average particle size value was recorded.

\subsection{Interfacial Tension (IFT)}

IFT between $2 \mu \mathrm{L}$ droplet crude oil and optimum concentration of PDOS solution were measured using spinning drop tensiometer TX 500, Texas. Surfactant solution with crude oil was spun at $6000 \mathrm{rpm}$ and $70 \mathrm{oC}$. Density difference between both liquids was used as an input to calculate the IFT, and a stable IFT after ten minutes was recorded.

\subsection{Zeta Potential Measurement}

Zeta potential of the PDOS solutions was determined using a HORIBA Nano Particle Analyzer SZ-100 with a measurement range of zeta potential $200 \mathrm{mV}$ to $200 \mathrm{mV}$. The zeta potential was measured in electrolyte solution of $0.01 \mathrm{M}$ sodium chloride, the capillary cell was filled with PDOS solutions in concentrations of $0.05,0.1,0.3,0.5$, and $1 \mathrm{wt} \%$, and these were placed inside the instrument for measuring the zeta potential at a temperature of $25^{\circ} \mathrm{C}$.

\section{RESULTS AND DISCUSSION}

\subsection{Aqueous Stability}

Droplet size of PDOS solutions was determined by particle size analyzer using the DLS technique. Table 1 shows the droplet size of various PDOS solutions in deionized water as a dispersant, as prepared on the first day. The recorded data show a coefficient of variation (COV) value of 0.06 to $1.79 \%$; measurements are considered sufficient when the COV is less than 3\% (Horiba, 2014). Aqueous stability of PDOS in various concentrations was assessed by monitoring the change in droplet size distribution and the mean droplet size over five days of storage at room temperature, as shown in Figure 1.

Table 1 Droplet size of PDOS in various concentrations

\begin{tabular}{crrrrr}
\hline \multirow{2}{*}{ Entry } & \multicolumn{5}{c}{ Average hydrodynamic diameter Z (nm) } \\
\cline { 2 - 6 } & $0.05 \mathrm{wt} \%$ & $0.10 \mathrm{wt} \%$ & $0.30 \mathrm{wt} \%$ & $0.50 \mathrm{wt} \%$ & $1 \mathrm{wt} \%$ \\
\hline 1 & 155.00 & 150.10 & 157.60 & 160.30 & 155.80 \\
2 & 156.30 & 145.20 & 159.30 & 157.40 & 153.00 \\
3 & 156.80 & 149.40 & 156.70 & 160.60 & 153.30 \\
STDEV & 0.93 & 2.65 & 1.32 & 1.77 & 1.54 \\
Mean (nm) & 156.03 & 148.23 & 157.87 & 159.43 & 154.03 \\
COV (\%) & 0.60 & 1.79 & 0.84 & 1.11 & 1.00 \\
\hline
\end{tabular}

From the results shown in Figure 1 it can be seen that the droplet size of PDOS was stable in various concentrations over five days of observation, except for $0.05 \mathrm{wt} \%$ in which droplet size increased on the third day. This indicates that aqueous stability depended on the concentration of surfactant.

Table 2 shows polydispersity, which is an estimation of the distribution width. Polydispersity indices of a sample in solution occur in the range 0.05 to 0.7 , with a polydispersity index of 0.05 only being found for monodisperse standard particles (Septiyanti, 2016). A polydispersity index of greater than 0.7 indicates that the sample being analyzed contains a very wide size distribution and therefore DLS is not a suitable method for analyzing it (Malvern, 2011). Based on Table 2, the polydispersity index of PDOS surfactant over the increasing concentrations was $0.2,0.3,0.4$, and 0.5 . Samples with polydispersity index values of 0.1 to 0.4 are classified as of moderately polydisperse distribution type, while above 0.4 is classified as broad polydisperse 
distribution type (Nobbman, 2014). Surfactants not dispersed perfectly occur due to agglomeration which leads to the occurrence of diverse particle size and hence the polydispersity index increases.

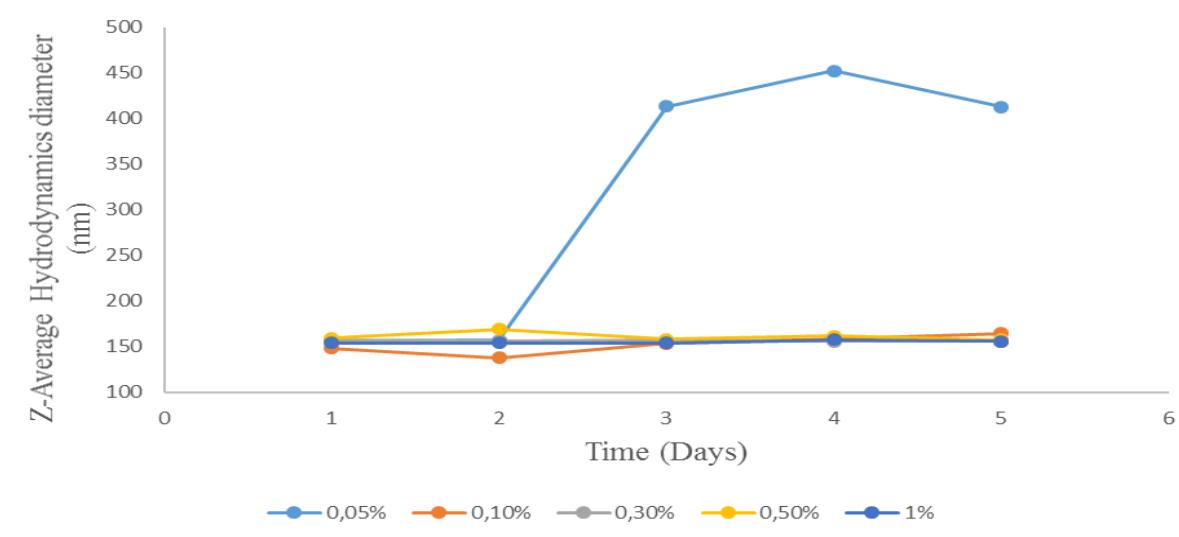

Figure 1 Aqueous stability of PDOS over five days

Table 2 Polydispersity index of PDOS in various concentrations

\begin{tabular}{cccccc}
\hline \multirow{2}{*}{$\begin{array}{c}\text { Time } \\
\text { (days) }\end{array}$} & \multicolumn{5}{c}{ Polydispersity index } \\
\cline { 2 - 6 } & $0.05 \mathrm{wt} \%$ & $0.10 \mathrm{wt} \%$ & $0.30 \mathrm{wt} \%$ & $0.50 \mathrm{wt} \%$ & $1 \mathrm{wt} \%$ \\
\hline 1 & 0.3 & 0.2 & 0.2 & 0.2 & 0.2 \\
2 & 0.3 & 0.2 & 0.2 & 0.2 & 0.2 \\
3 & 0.5 & 0.4 & 0.2 & 0.2 & 0.2 \\
4 & 0.5 & 0.4 & 0.2 & 0.2 & 0.2 \\
5 & 0.5 & 0.4 & 0.2 & 0.2 & 0.2 \\
\hline
\end{tabular}

\subsection{Interfacial Tension (IFT)}

The graph of IFT and CMC of the PDOS surfactant in Figure 2 supports the results of aqueous stability demonstrated in Figure 1. According to Vert (2012), micelle formation and stability are concentration dependent; the surfactant can exist as different phases depending upon the concentration of the sample.

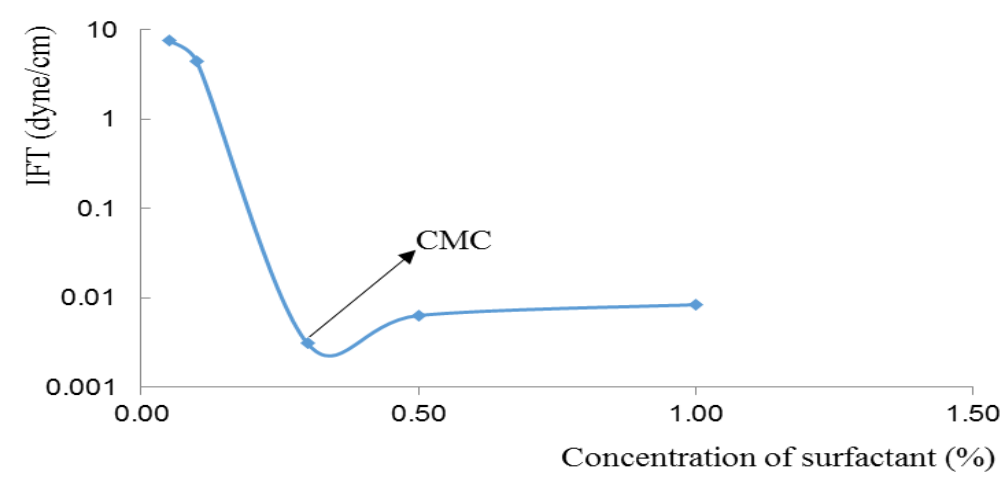

Figure 2 IFT and CMC of PDOS

Meanwhile, surfactant micelle characterization using DLS reported by Malvern (2006) explains that the intensity of scattered light detected from each concentration below the critical micelle 
concentration (CMC) was similar to that obtained from water. In addition, the autocorrelation functions obtained showed very poor signal-to-noise ratios, that is, very low intercepts and no size distribution information could be obtained from this data. However, once the CMC was reached, the intensity of scattered light increased due to the presence of micelles and the intercepts obtained in the correlation functions are much higher.

The CMC of PDOS surfactant was $0.3 \%$ as shown in Figure 2. CMC is the concentration at which micelles form. The characteristics of micelles can be controlled by small changes in the chemical structure of the surfactant molecules or by varying the conditions of the disperse phase by changing the $\mathrm{pH}$, ionic strength, and temperature (Birdi, 1997). For these cases, the micelle size can be affected by the concentration of surfactant with measuring the droplet size as a function of time in Figure 1. Figure 2 also shows that the IFT between the PDOS surfactant in aqueous solution and crude oil was measured to be around $10^{-3} \mathrm{dyn} / \mathrm{cm}$ at concentrations of $0.3,0.5$, and $1 \mathrm{wt} \%$.

\subsection{Zeta Potential}

Zeta potential is related to the surface charge of PDOS surfactants. Zeta potential is also known as electrokinetic potential, that is, the potential at the slipping shear plane of colloid particles moving under the influence of an electric field (Kaszuba et al., 2010). One of the most popular uses of zeta potential data is to relate it to colloid stability. Guidelines classify nanoparticle dispersions with zeta potential values of $\pm 0-10 \mathrm{mV}, \pm 10-20 \mathrm{mV}, \pm 20-30 \mathrm{mV}$, and $> \pm 30 \mathrm{mV}$ as highly unstable, relatively stable, moderately stable and highly stable, respectively (Patel et al., 2011). Figure 3 and Table 3 shows that the zeta potential of PDOS surfactant without additions of salt indicates that PDOS surfactant in concentrations of $0.05,0.1,0.3,0.5$ and $1 \%$ were highly stable. The various concentrations had zeta potentials of $96.8,-90.5,-89.6,-82.3$, and $-64.4 \mathrm{mV}$, respectively, and conductivity increased with increasing concentration.

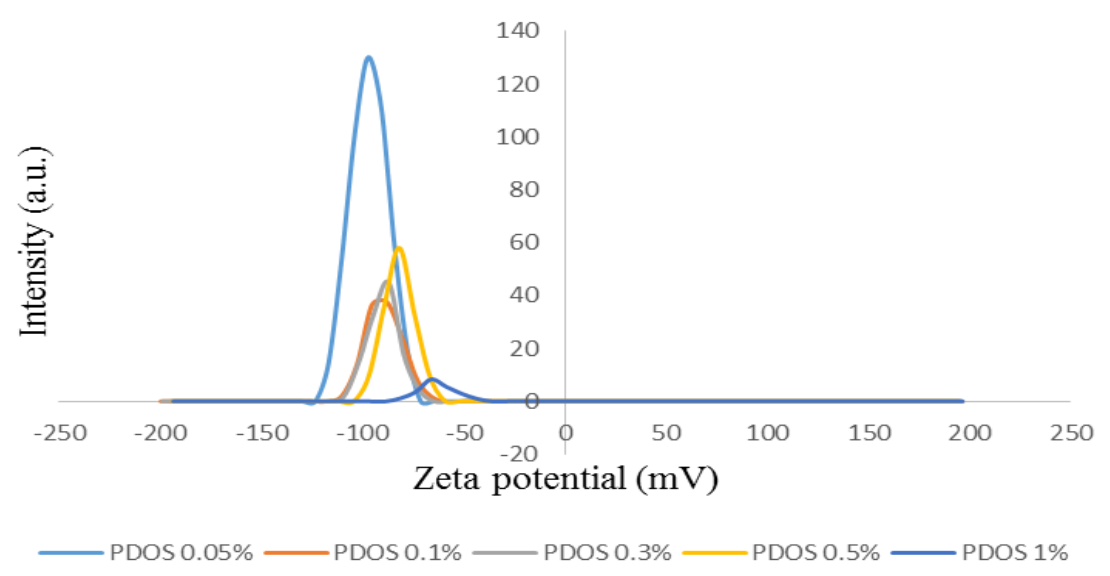

Figure 3 Zeta potential of PDOS in various concentrations

Table 3 Zeta potential of PDOS surfactant without addition of salt

\begin{tabular}{ccc}
\hline Concentration $(\mathrm{wt} \%)$ & Zeta potential $(\mathrm{mV})$ & Conductivity $(\mathrm{mS} / \mathrm{cm})$ \\
\hline 0.05 & -96.8 & 0.081 \\
0.1 & -90.5 & 0.106 \\
0.3 & -89.6 & 0.122 \\
0.5 & -82.3 & 0.155 \\
1.0 & -64.4 & 0.254 \\
\hline
\end{tabular}


Meanwhile, Figure 4 and Table 4 show that the zeta potential of PDOS surfactant with additions of salt was moderately stable in concentrations of $1 \mathrm{wt} \%$ and that the addition of salt affected the zeta potential of surfactant.

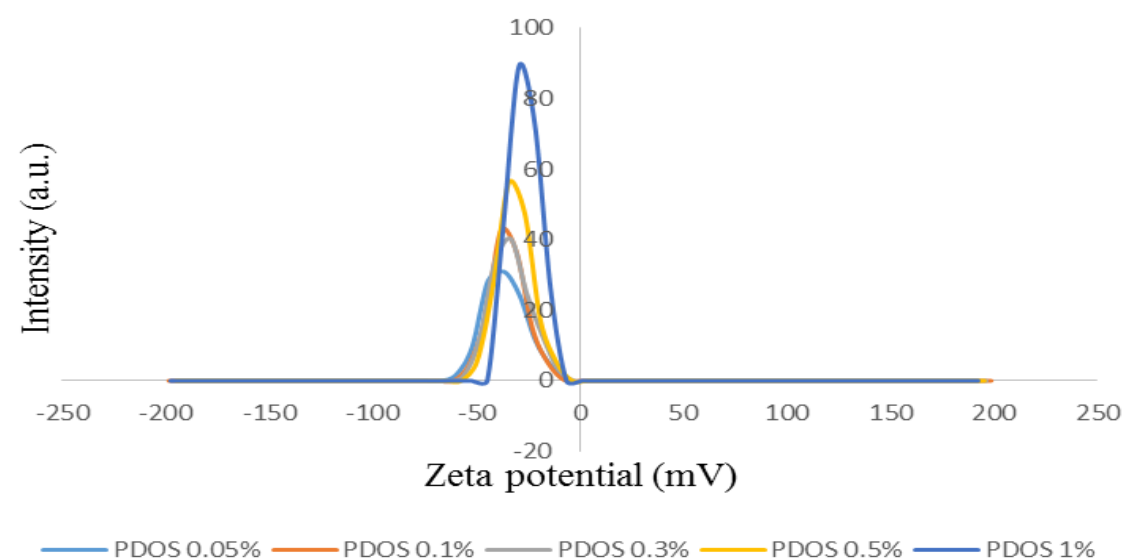

Figure 4 Zeta potential of PDOS in various concentrations with addition of salt

Table 4 Zeta potential of PDOS Surfactant with additions of salt

\begin{tabular}{ccc}
\hline Concentration $(\mathrm{wt} \%)$ & Zeta potential $(\mathrm{mV})$ & Conductivity $(\mathrm{mS} / \mathrm{cm})$ \\
\hline 0.05 & -37.2 & 1.020 \\
0.1 & -35.2 & 0.984 \\
0.3 & -34.6 & 1.049 \\
0.5 & -31.6 & 1.066 \\
1.0 & -27.0 & 1.090 \\
\hline
\end{tabular}

As is evident, a high value of zeta potential indicates the likelihood that a suspension will be stable. Conversely, a low zeta potential means that the suspension will aggregate. If the results are compared with the aqueous stability demonstrated in Figure 1, although PDOS surfactant with concentration of $0.05 \%$ has a high value of zeta potential with additions of salt, there is no guarantee that surfactant will be stable for five days. This is because zeta potential measurements are made on quiescent systems (i.e. at rest). During formulation and production stages many suspensions are often subject to shear (by pumping or stirring) or heat and this additional mechanical or thermal energy is often sufficient to promote aggregation (Fairhurst, 2013).

\section{CONCLUSION}

Aqueous stability of PDOS surfactant for five days was observed in concentrations of 0.1 to 1 wt\%, during which the droplet size became unstable from the third day at the lowest concentration $(0.05 \mathrm{wt} \%)$. Polydispersity indices of PDOS at concentrations of 0.05 and $0.1 \%$ were 0.3 and 0.5 , meanwhile at concentrations of 0.3 to $1 \mathrm{wt} \%$ polydispersity was measured as 0.2 . The polydispersity index of PDOS classified it as being of a polydisperse distribution type. The CMC of PDOS was $0.3 \%$ and IFT of PDOS above the CMC was around $10^{-3} \mathrm{dyne} / \mathrm{cm}$. Results of the zeta potential of PDOS without the addition of salt at concentrations of $0.05,0.1$, $0.3,0.5$, and $1 \%$ were highly stable, being recorded as $-96.8 ;-90.5,-89.6,-82.3$, and $-64.4 \mathrm{mV}$, respectively, and conductivity increased with increasing concentration. The zeta potential of PDOS with addition of salt was moderately stable at a concentration of $1 \%$. Although PDOS 
with concentration of $0.05 \%$ demonstrated a high value of zeta potential with the addition of salt, there is no guarantee that the PDOS surfactant solution would be stable for five days.

\section{ACKNOWLEDGEMENT}

The authors thank Ir. Letty Brioletty M.T from PPPTMGB LEMIGAS as a partner in the application of this study of polymeric surfactants in EOR, and Dr. Eng Agus Haryono as the Director of the Research Center for Chemistry LIPI. The financial support received from DIPA is fully acknowledged.

\section{REFERENCES}

Babu, K., Pal, N., Saxena, V.K., Mandal, A., 2016. Synthesis and Characterization of a New Polymeric Surfactant for Chemical Enhanced Oil Recovery. Korean Journal of Chemical Engineering, Volume 33(2), pp. 711-719

Birdi, K.S., 1997. Handbook of Surface and Colloid Chemistry. USA: CRC Press

Domínguez, A., Fernández, A., González, N., Iglesias, E., Montenegro, L., 1997. Determination of Critical Micelle Concentration of Some Surfactants by Three Techniques. Journal of Chemical Education, Volume 74(10), pp. 1227-1231

Fairhurst, D., 2013. An Overview of the Zeta Potential Part 3: Uses and Applications. Particle Sciences, Inc. American Pharmaceutical Review

Horiba Instrument Catalog, 2014. A Guidebook to Particle Size Analysis. Horiba Instrum. Cat., pp. 1-32

Irawan, Y., Juliana, I., 2015. Effect of Temperature on Manufacturing Process of Polyethylene Glycol Dioleate (PDO). The $3^{\text {rd }}$ Bali International Seminar on Science and Technology (BISSTECH)

Irawan, Y., Juliana, I., Adilina, I.B., 2017. Synthesis and Characterization of Palm Oil and Polyethylene Glycol Based Polymeric Surfactants. The 4th Bali International Seminar on Science and Technology (BISSTECH) and The 1st International Joint Conference on Science and Technology (IJCST).

Kaszuba, M., Corbett, J., Watson, F.M., Jones, A., 2010. High-concentration Zeta Potential Measurements using Light-scattering Techniques. Philos Trans A Math. Phys. Eng. Sci., Volume 368, pp. 4439-4451

Malvern Application Note, 2006. Surfactant Micelle Characterization using Dynamic Light Scattering. The Journal of Physical Chemistry B, pp. 1-5

Malvern, 2011. Dynamic Light Scattering Common Terms Defined., pp. 1-6

Mandavi, R., Sar, S.K., Rathore, N., 2008. Critical Micelle Concentration of Surfactant, MixedSurfactant and Polymer by Different Method at Room Temperature and Its Importance. Oriental Journal of Chemistry, Volume 24(2), pp. 559-564

Nagy, R., Bartha, L., Vágó, Á., 2014. Study on Characteristics of Micelles Formed by Surfactants and Polymer Mixtures for Enhanced Oil Recovery. Chemical Engineering Transactions, Volume 36, pp. 217-222

Nakahara, Y., Kida, T., Nakatsuji, Y., Akashi, M., 2005. New Fluorescence Method for the Determination of the Critical Micelle Concentration by Photosensitive Monoazacryptand Derivatives. Langmuir, Volume 21(15), pp. 6688-6695

Nobbmann, U., 2014. Polydispersity - What Does It mean for DLS and Chromatography? www.Material-Talks.com, (23 October 2014)

Patel, P.R, Agrawal, Y.K. 2011. Nanosuspension: An Approach to Enhance Solubility of Drugs. Journal of Advance Pharmaceutical Technology \& Research, Volume 2(2), pp. 8187 
Septiyanti, M., Fahmiati, S., Meliana, Y., 2016. Pengaruh Konsentrasi Sampel Terhadap Akurasi Pengukuran Diameter Partikel Nanoemulsi (Effect of Sample Concentration on Measurement of Nanoemulsion Particle Diameter). Annual Meeting on Testing and Quality, LIPI., pp. 121-127

Vert, M., Doi, Y., Hellwich, K.-H., Hess, M., Hodge, P., Kubisa, P., Rinaudo, M., Schué, F., 2012. Terminology for Biorelated Polymers and Applications (IUPAC Recommendations 2012). Pure and Applied Chemistry, Volume 84(2), pp. 377-410 